\title{
THE ASSESSMENT OF THE BOSTANLIQ DISTRICT (UZBEKISTAN REPUBLIC) BASED ON THE WIND ENERGY POTENTIAL
}

\begin{abstract}
The idea of achieving energy security and lowering the dependence on the global hydrocarbon market is at the top of the agenda in many countries. Most of them consider switching from traditional energy sources to renewable ones as one of the ways to reduce fuel import. This concept absolutely conforms to one of the UN Sustainable Development Goals (Goal no. 7, "Affordable and Clean Energy"). In May 2019, the Government of Uzbekistan Republic adopted the Law on the Use of Renewable Energy Sources (RES). By 2030, Uzbekistan is going to increase the share of RES in the total structure of electricity generation up to $25 \%$ (currently it is at $10 \%$ ), by building solar and wind farms with a total installed capacity of 5,000 MW and 3,000 MW, respectively. The energy-deficient Bostanliq district of the Tashkent region has become one of the places of interest, where transport infrastructure, recreation services, and renewable energy will be developed. The purpose of this study was a multivariate analysis, considering the meteorological, ecological, and socio-economic characteristics of the Bostanliq district, leading to the selection of the optimal location for the wind farm. The assessment map based on the results of this analysis made it possible to identify areas that are most suitable for the location of wind power plants. The assessment method, that was used in this work, is also applicable to other regions of the world.
\end{abstract}

KEYWORDS: wind energy, spatial analysis, Uzbekistan, Bostanliq district, GIS.

\section{INTRODUCTION}

Renewable energy sources become more prominent in the global energy mix, as they provide more than $10 \%$ of global electricity demand. In developed countries, for example, in Germany, at the beginning of 2020 , the installed capacity of renewable energy plants reached $46 \%$ of all electricity generated (125 GW). Developing countries also showes success in renewable energy development. This is due to the increased demand for energy, the depletion of fossil fuel and energy resources, the constant decline in technology prices, the need to reduce the carbon footprint, and the desire to gain energy independence. The United Nations characterizes the energy transition as one of the main sustainable development goals [Berezkin, Sinyugin, 2018].

Recently, some countries and regions have initiated comprehensive spatial studies wind energy development potential in different parts of their territories. These studies incorporated meteorological, socio-economic, and geoecological parameters. One of the first studies in this area was the research of Rob van Haaren and Vasilis Fthenakis, who assessed the wind energy potential of the New York state. When the organization of renewable energy generation is being prepared, they took into account the degree of visual and noise impact, potential disturbance of vegetation and spawning grounds, distance from wetlands, roads and power lines, etc. [Van Haaren, Fthenakis, 2011]. Their concept of a multivariate assessment was endorsed by scientists from the

Lomonosov Moscow State University, High School of Innovative Business, Leninskie Gory 1, 119991, Moscow, Russia, e-mail: yalbacheva@geogr.msu.ru 
Korea Institute of Energy Research. To assess the regions of South Korea in terms of the potential for the development of wind energy, experts added to the analysis the parameter of the remoteness of potential wind farms from protected areas, habitats of rare and endangered species, assessed the potential damage in case of an emergency, proximity to infrastructure facilities, etc. In total, they considered 57 factors [Kim et al., 2013]. Also in 2019, the analytical company Wind Minds conducted an evaluation of Vietnam territorypotential for wind energy development as government requested. As part of the research, the scientists also applied an integrated approach and, in addition to meteorological indicators, integrated the terrain, the land use characteristics, and even the marine vessel traffic along the coast [Sissingh, Arends, 2019].

It should be noted that multivariate analysis of territories for choosing a site for installing wind turbines is a rare instance; the consideration of meteorological or economic characteristics traditionally prevails. Geological, geomorphological, and environmental factors influencing the choice of the layout of the spatial distribution of wind farms are rarely taken into account.

\section{STUDY AREA}

Bostanliq district is located in the northeast of Uzbekistan, in the Tashkent region, where the spurs of the Western Tien Shan lie. On the north side, the region borders with Kazakhstan, and the border with Kyrgyzstan is on the east and northeast (Fig. 1).

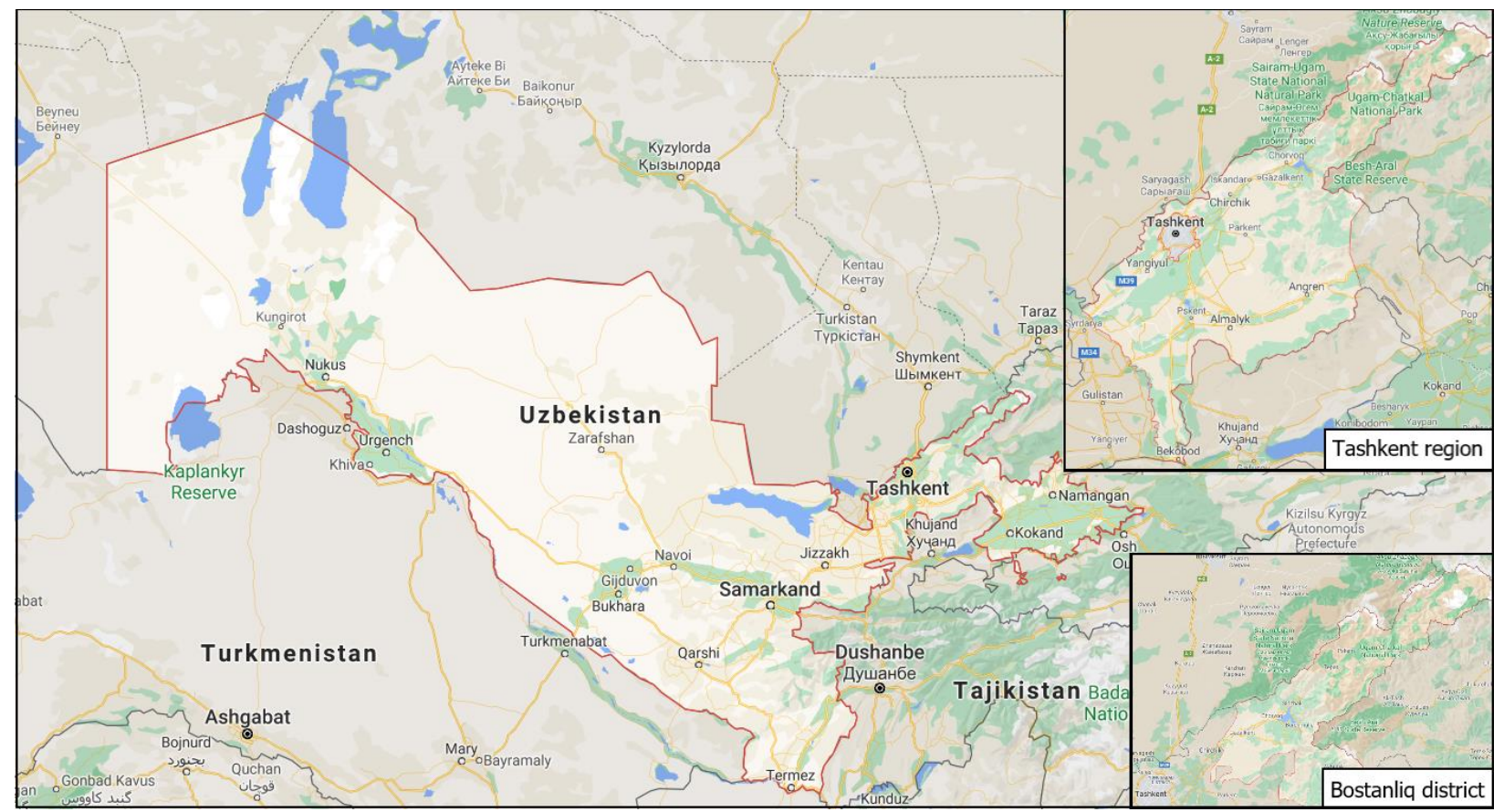

Fig. 1. Study area (Google Maps)

The relief is represented mainly by uplands, midlands, and highlands. The specifics of the bedrock dictate the wide presence of exogenous processes. The climate, in comparison with other regions of the Uzbekistan Republic, is humid; the annual amount of precipitation reaches 500-600 mm per year. The area is characterized by mountain-valley breezes and foehn winds [Belousov, 1986].

In the Bostanliq district, there are 24 rural communities, 17 urban settlements, one city (Gazalkent, the administrative center), and a large number of villages (Fig. 2). The share of the rural population reaches 60\% [Saliev, Fedorko, 2012]. This determines the leading role of agriculture in the current economy of the region; the Bostanliq district is one of the main suppliers of grain for the entire Tashkent region. Melon growing, vegetable growing, horticulture, viticulture, and cotton growing are also developed. Animal farming has also agreat importance. In 
total, there are 140 farms and 22 cooperative farms in the study area with tens of thousands of heads of cattle and small ruminants, poultry, and horses in herds [Islomov, Zhumataev, 2019].

The analysis covers most of the Bostanliq district populated area, with the exception of the frontier highland regions, due to the limitations of the field study of the expedition "Dynamics of landscapes and nature management of northeastern Uzbekistan" of the Department of Physical Geography and Landscape Science (Faculty of Geography, Lomonosov Moscow State University).

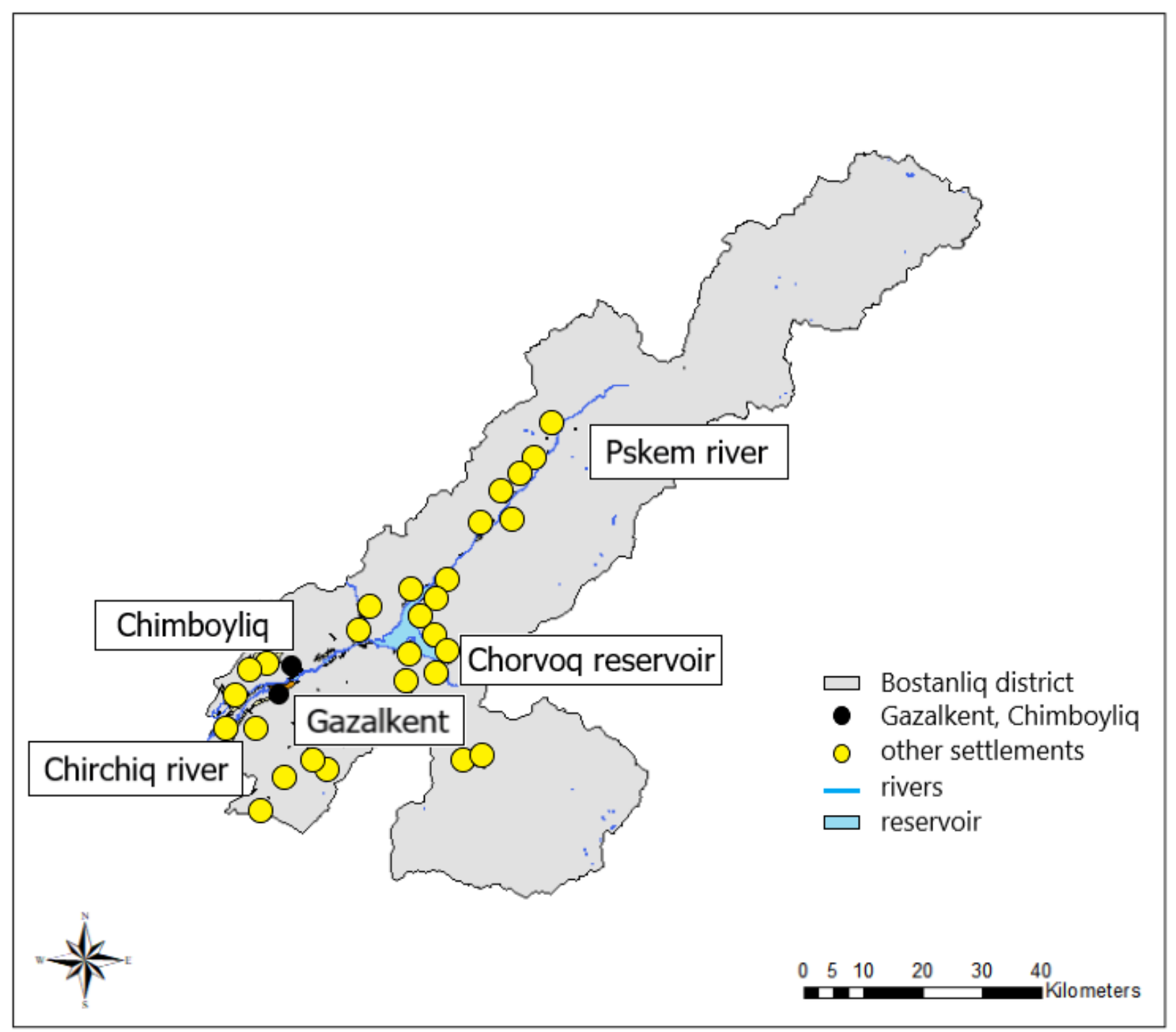

Fig. 2. Bostanliq district (by author)

\section{MATERIALS AND METHODS}

The research materials were based on theoretical and methodological works "Theoretical Framework of Alternative and Renewable Energy" [Elistratov, Kuznetsov, 2003], "Comprehensive renewable energy" [Sayigh, 2012], "Knowledge and landscape in wind energy planning" [Lee, 2017]; reference materials of Global Wind Atlas, NextGIS, data from international organizations (IUCN RedList, BirdLife International), materials of the Institute of Geology and Geophysics of the Academy of Sciences of Uzbekistan, international scientific groups researches [Juliev et al., 2017], data from digital elevation model ALOS, as well as fieldwork results of the 
expedition "Dynamics of landscapes and nature management of northeastern Uzbekistan" of the Department of Physical Geography and Landscape Science (Faculty of Geography, Lomonosov Moscow State University).

The main research methods were fieldwork, cartographic analysis, complex geoecological analysis, and GIS analysis.

\section{RESULTS AND DISCUSSION}

In 2020, the Council of People's Deputies of Uzbekistan discussed the main directions and goals of the integrated development of the Tashkent region for 2021-2022. Energy development is among the potential drivers of the economy. In the Bostanliq district, $\$ 1.048$ billion of foreign investments were attracted towards the construction of two hydroelectric power plants with a total installed capacity of $540 \mathrm{MW}^{1}$. There are also plans to build a wind park (100 hectares) for 36-50 wind power plants near the village of Chimboyliq. The total cost of the project is $\$ 900$ million. Sufficient wind energy potential (specific power up to $300 \mathrm{~W} / \mathrm{m}^{2}$ ), developed transport infrastructure, proximity to the end consumer (Gazalkent city), and the presence of power transmission lines determined the choice of a site for the construction of a wind farm. However, a comprehensive geoecological analysis carried out by the authors shows that the set of used characteristics was insufficient to justify such a choice.

The structure of this analysis included both traditionally used characteristics, as well as geological, geomorphological, and ecological:

1. Meteorological:

- $\quad$ average annual wind speed,

- wind capacity.

2. Socio-economical:

- distance from roads,

- distance from railways,

- distance from railway stations,

- distance from settlements,

- distance from power lines,

- distance from touristic sites.

3. Geological and geomorphological:

- underlying rock structures,

- $\quad$ presence of faults,

- $\quad$ seismicity,

- historical earthquake epicenters,

- presence of landslides,

- slopes,

- $\quad$ relative elevation,

- distance from mining sites.

4. Ecological:

- $\quad$ occurrence of Red List species of plants and animals,

- distance from Important Bird Areas,

- landscape characteristics.

Toshkent viloyati hokimligi: http://toshvil.uz/oz/toskent-viloatini-rivozlantiris-bujica-ustuvor-junalislarmuokama-kilindi (Accessed 22.04.2021). 
The multivariate analysis leads to the following conclusions; ones that made it possible to propose alternative options for the location of the construction site.

1. Meteorological indicators are decisive since they directly affect the efficiency of the wind turbine, and these figures determine whether the selected area will have the necessary wind energy potential for the development of the industry. The study uses calculations for a height of 50 meters from the ground level surface.

It was discovered that in the Bostanliq district the prevailing wind speeds are from 2 to 8 $\mathrm{m} / \mathrm{s}$, and the most favorable is the territory of the Chirchiq River Valley. There are no average annual wind speeds above $16 \mathrm{~m} / \mathrm{s}$ that are considered to be threatening to the wind turbines. Spatial analysis of the wind energy potential within the region based on meteorological characteristics showed that the specific power of the wind flow in a densely populated area with a center of Gazalkent city and smaller settlements reaches $100 \mathrm{~W}$ per sq. meter and creates an unsuitable zone for the wind turbines operation. The maximum wind energy potential (more than $500 \mathrm{~W}$ per sq. meter) is observed in the lower course of the Pskem River; the area on the left bank of the watercourse is especially rich in wind energy resources. In general, the Bostanliq district has average characteristics of wind energy potential, which can satisfy the needs of the administrative territory.

2. In terms of the socio-economic characteristics, the most suitable regions are also located in the Chirchiq River Valley. The end of the Tashkent railway so far is in the administrative center, the city of Gazalkent; both sides of the valley have a developed road and power line network, however, all of this is concentrated below the Chorvoq reservoir. As you move further into the mountains upstream of the Pskem River, the number of roads and power lines is decreasing. However, it is unlikely that it will significantly increase the expenditures for wind energy projects.

3. The geological and geomorphological factors must be taken into account since wind power plants are heavy structures that need a solid foundation protecting them against unfavorable and dangerous endogenous and exogenous geological and geomorphological phenomena. The study area is confined to a network of tectonic faults, which explains the seismicity of magnitude 6.5 on $70 \%$ of the study area. In general, according to the Ministry of Emergency Situations of Uzbekistan and the State Committee for Architecture and Construction, the frequency of 7-point earthquakes repeats once every 50-100 years and 8point earthquakes occur approximately once every $100-400$ years. Yet this is a predictive estimate. The more accurate characterization of the territory was made possible through the listing of the historical earthquake epicenters locations of the 20th century, their magnitude ranging from 4.3 to 6.5 points. As a result, we have identified areas of potential development of the unfavorable or dangerous geological phenomena that pose threats to the strength of wind turbine structures.

Special attention was given to the underlying rock structures, which contribute to ensuring the stability of such enormous structures as modern industrial wind turbines. The ranking was based on the scale of rock hardness developed by M. Protodyakonov ${ }^{1}$, but with the reduced amount of the evaluation categories. Four categories of different hardness were distinguished: a) chalk, gypsum, marls, clays, loess, and gravels have the minimum

1 Classification of rock hardness (Protodyakonov scale): https://rosmining.ru/wpcontent/uploads/2014/11/\%D0\%9A\%D0\%BB\%D0\%B0\%D1\%81\%D1\%81\%D0\%B8\%D1\%84\%D0\%B8\% D0\%BA $\%$ D0\%B0\%D1\%86\%D0\%B8\%D1\%8F-

$\% \mathrm{D} 0 \% \mathrm{~B} 3 \% \mathrm{D} 0 \% \mathrm{BE} \% \mathrm{D} 1 \% 80 \% \mathrm{D} 0 \% \mathrm{BD} \% \mathrm{D} 1 \% 8 \mathrm{~B} \% \mathrm{D} 1 \% 85-$

$\% \mathrm{D} 0 \% \mathrm{BF} \% \mathrm{D} 0 \% \mathrm{BE} \% \mathrm{D} 1 \% 80 \% \mathrm{D} 0 \% \mathrm{BE} \% \mathrm{D} 0 \% \mathrm{~B} 4-\% \mathrm{D} 0 \% \mathrm{BF} \% \mathrm{D} 0 \% \mathrm{BE}-$

$\% \mathrm{D} 0 \% 9 \mathrm{~F} \% \mathrm{D} 1 \% 80 \% \mathrm{D} 0 \% \mathrm{BE} \% \mathrm{D} 1 \% 82 \% \mathrm{D} 0 \% \mathrm{BE} \% \mathrm{D} 0 \% \mathrm{~B} 4 \% \mathrm{D} 1 \% 8 \mathrm{C} \% \mathrm{D} 1 \% 8 \mathrm{~F} \% \mathrm{D} 0 \% \mathrm{BA} \% \mathrm{D} 0 \% \mathrm{BE} \% \mathrm{D} 0$

$\%$ BD $\%$ D0\%BE\%D0\%B2\%D1\%83.pdf (Accessed 27.04.2021) 
hardness, b) sandstones, limestones, conglomerates, and slates have slightly higher hardness, c) dolomites, marble, and shale sandstones are characterized by medium-to-high hardness, and d) quartzite, basalt, andesite, dacite, granite, gneiss, syenite, diorite, and monzonite have the highest degree of hardness. The last category is the most favorable for the construction of wind power plants. Considering a large number of loess formations and the prevalence of unstable Quaternary, Carboniferous, and Paleogene loose sediments and unstable rocks in the valley, such an assessment made it possible to determine risk areas for dangerous exogenous geomorphological processes.

The underlying rock characteristics and the seismicity of the territory allow us to assess the activity of landslide processes. In total 64 landslide concentrated mainly around the Chorvoq reservoir (Fig. 3) bodies of different ages, sizes, and degrees of activity were identified. These geological and geomorphological objects are moving occasionally, posing a danger to the adjacent territories; also, due to the nature of the underlying rocks, they cannot serve as a reliable foundation for wind power plants.

In addition to the specified parameters, this pool considered the steepness of the slopes, which is of decisive technical importance for the construction of wind turbines, the relative height (affecting the wind speed), and the distance from mining sites (anthropogenic enhancement of seismicity).

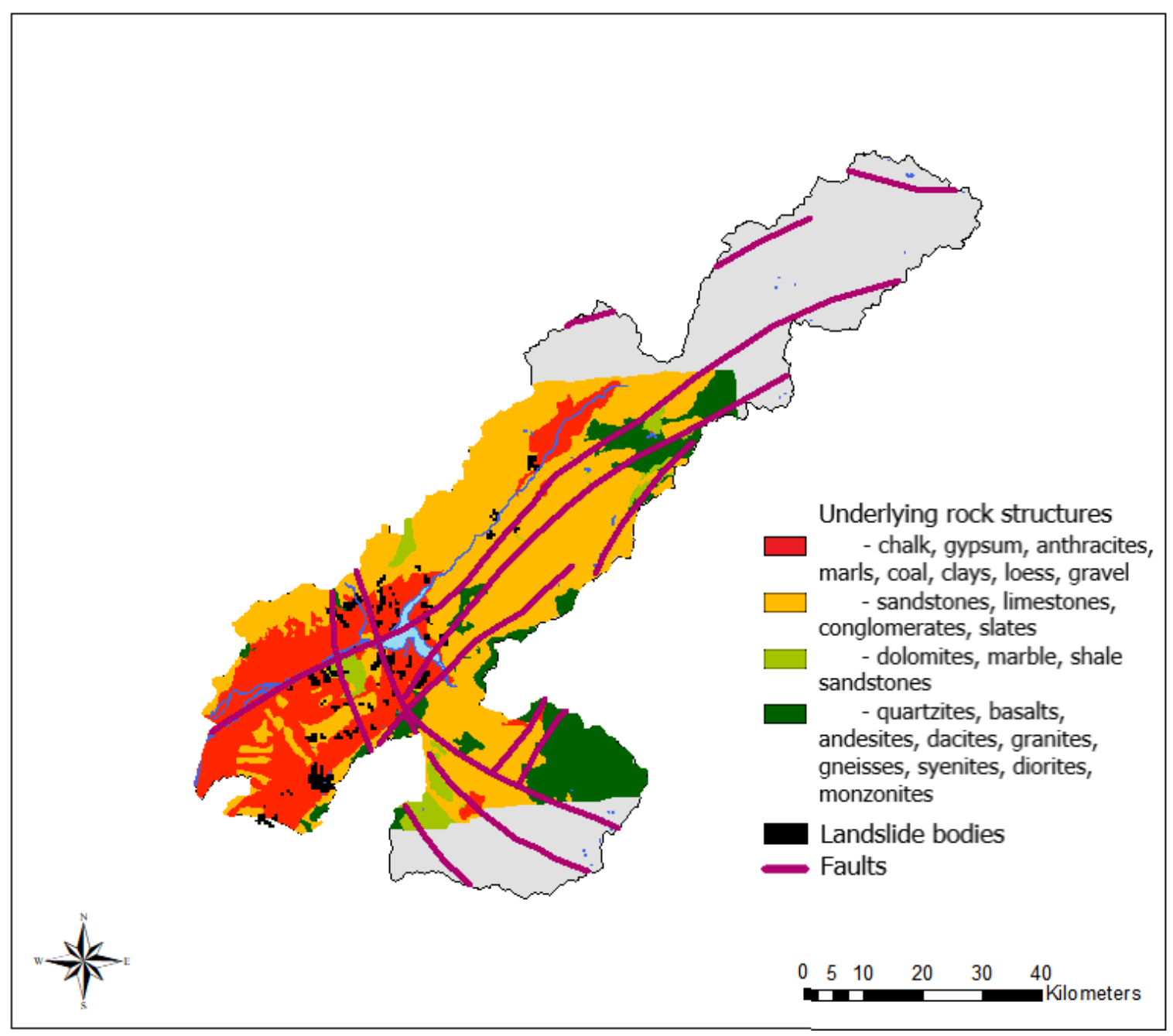

Fig. 3. Faults, underlying rock structures and landslide bodies of the study area (by author) 
4. The ecological analysis is heavily based on the concept of environmental friendliness of renewable energy sources in comparison with traditional sources. Any anthropogenic activity is a violation of the natural conditions of the territory. In this study, we examined the potential impact of the development on the habitats of rare and endangered animal species. Based on the data on the Red List species ranges, the study area was divided into four zones: areas where habitats of 17, 18, 19, and 20 species are located, respectively. Unsurprisingly, more pristine areas that are less suitable for the wind turbines installation turned out to be concentrated in mountainous areas on the territory of the Chatkal reserve; the most suitable areas (with a lower occurrence of rare species) are in the most densely populated part in the southwest of the Bostanliq district. The habitats of locally endemic species, Menzbier's marmot (Marmota menzbieri) are regarded separately. As the marmot lives in the surface soils layer that is most exposed to heavy turbine vibrations, its' range can potentially change, and that can lead to the extinction of this endangered species.

Based on the same reasoning, the location of Important Bird Areas, habitats, and foraging grounds for birds, which is allocated by the international organization for the protection of birds and the preservation of their habitat BirdLife International, was taken into account. The last parameter considered to characterize modern landscapes, which is necessary for predicting possible conflicts of nature management. Taking into consideration the upper mentioned factors, as well as the patterns of modern land use, the landscapes were assessed as follows in terms of the degree of suitability for the installation of wind turbines. The unsuitable areas are water bodies; hilly-ridged low mountains and foothills with a loess cover, with gardens and arable lands, heavily dissected by ravine network; terraced river valleys with loess deposits with gardens and arable lands; as well as valleys with herbshrub communities and deciduous forests along the riverbeds. The moderately suitable areas include the medium-dissected hilly-ridged foothills with gardens and arable lands and more impact-resistant rocks (conglomerates, sandstones), and the slopes of middle highland medium-dissected ridges with a similar substrate. Alpine landscapes are considered suitable due to the hardness of the underlying rocks. The optimal (most suitable) are the middle highland medium-dissected ridges with plateau-like peaks, composed of igneous and hard carbonate rocks.

To visualize and integrate the results of the multivariate analysis, the entire array of maps and data was processed in the ArcMap program of the ArcGIS software package. The Euclidean distances were calculated for linear and point features using the Euclidean Distance tool. Then, the addressed characteristics were normalized as a part of the quantitative and qualitative assessment of the territory. Then the characteristics were ranked according to the degree of suitability for the development of wind farms. As a result, we obtained a four-part general classification scheme, where all parameters were described as follows: unsuitable (1), moderately suitable (2), suitable (3), and optimal (4) (Table 1).

The final step was to synthesize all available normalized and ranked information through the creation of a weighted suitability layer in ArcMap. The procedure consisted of overlaying raster data for each parameter, multiplying each by the weight assigned to them, and then summing them up. The assignment of weight to the characteristics was carried out expertly according to their significance for the final assessment: from 0.0942 to 0.01 . Based on the rules of the Weighted Sum tool, the sum should be equal to 1.0. Following the calculations, a map was built; this map is assessing the potential of the territory of the Bostanliq district for the development of wind energy based on the analysis of 20 physical-geographical and socio-economic parameters (Fig. 4). 
Table 1. Normalization and ranking of the assessed characteristics

\begin{tabular}{|c|c|}
\multicolumn{2}{c}{ Meteorological } \\
\hline Characteristic & $\begin{array}{c}\text { Normalization } \\
\text { and ranking }\end{array}$ \\
\hline & $1-$ less than 250 \\
$\mathrm{~W} / \mathrm{m}^{2} ;$ \\
& $2-200-400 \mathrm{~W} / \mathrm{m}^{2} ;$ \\
& $3-400-600 \mathrm{~W} / \mathrm{m}^{2} ;$ \\
Wind capacity & $4-$ more than 600 \\
& $\mathrm{~W} / \mathrm{m}^{2}$ \\
\hline & $1-$ less than $2 \mathrm{~m} / \mathrm{s} ;$ \\
& $2-2-8 \mathrm{~m} / \mathrm{s} ;$ \\
Average annual & $3-12-16 \mathrm{~m} / \mathrm{s} ;$ \\
wind speed & $4-8-12 \mathrm{~m} / \mathrm{s}$ \\
\hline
\end{tabular}

\begin{tabular}{|c|c|}
\hline Roads & $\begin{array}{c}1-\text { more than } 7500 \\
\mathrm{~m} ; \\
2-3500-7500 \mathrm{~m} ; \\
3-1500-3500 \mathrm{~m} ; \\
4-0-1500 \mathrm{~m}\end{array}$ \\
\hline Railways & $\begin{array}{c}1-\text { more than } \\
15000 \mathrm{~m} ; \\
2-5000-15000 \\
\mathrm{~m} ; \\
3-1500-5000 \mathrm{~m} ; \\
4-0-1500 \mathrm{~m}\end{array}$ \\
\hline Railway stations & $\begin{array}{c}1-\text { more than } \\
15000 \mathrm{~m} ; \\
2-5000-15000 \\
\mathrm{~m} ; \\
3-1500-5000 \mathrm{~m} ; \\
4-0-1500 \mathrm{~m}\end{array}$ \\
\hline Power lines & $\begin{array}{c}1-\text { more than } 7500 \\
\mathrm{~m} ; \\
2-3500-7500 \mathrm{~m} ; \\
3-1500-3500 \mathrm{~m} ; \\
4-0-1500 \mathrm{~m}\end{array}$ \\
\hline Settlements & $\begin{array}{c}1-\text { more than } \\
30000 \mathrm{~m} ; \\
2-10000-30000 \\
\mathrm{~m} ; \\
3-5000-10000 \\
\mathrm{~m} ; \\
4-0-5000 \mathrm{~m}\end{array}$ \\
\hline Touristic sites & $\begin{array}{c}1-0-1000 \mathrm{~m} ; \\
2-1000-3000 \mathrm{~m} ; \\
3-3000-10000 \\
\text { m; } \\
4-\text { more than } \\
10000 \mathrm{~m}\end{array}$ \\
\hline
\end{tabular}

Socio-economic

\begin{tabular}{c|c|} 
Characteristic & $\begin{array}{c}\text { Normalization } \\
\text { and ranking }\end{array}$ \\
\hline
\end{tabular}

Geological and geomorphological

\begin{tabular}{l|c|} 
Characteristic & Normalization \\
\hline
\end{tabular}

and ranking

$6,7,9,10,11$

$2-5,8$

\begin{tabular}{l|l} 
medium-scale & $4-3,4$ \\
\hline
\end{tabular}

the Bostanliq

district

\begin{tabular}{l|l} 
Red List species & $1-20$ species; \\
\hline & $2-19$ species;
\end{tabular}

$2-19$ species;

Menzbier's

marmot (Marmota

menzbieri)

- more than

$-0-10000$

$2-10000-30000$

$\mathrm{m}$;

Important Bird

Areas

4 - more than $60000 \mathrm{~m}$

\begin{tabular}{|c|c|}
\hline Faults & $\begin{array}{c}1-0-3000 \mathrm{~m} ; \\
2-3000-5000 \mathrm{~m} ; \\
3-5000-20000 \\
\mathrm{~m} ; \\
4-\text { more than } \\
20000 \mathrm{~m}\end{array}$ \\
\hline $\begin{array}{l}\text { Earthquake } \\
\text { epicenters }\end{array}$ & $\begin{array}{c}1-0-5000 \mathrm{~m} ; \\
2-5000-10000 \\
\mathrm{~m} ; \\
3-10000-20000 \\
\mathrm{~m} ; \\
4-\text { more than } \\
20000 \mathrm{~m}\end{array}$ \\
\hline Landslide bodies & $\begin{array}{c}1-0-1000 \mathrm{~m} ; \\
2-1000-3500 \mathrm{~m} ; \\
3-3500-5000 \mathrm{~m} ; \\
4-\text { more than } 5000 \\
\mathrm{~m}\end{array}$ \\
\hline $\begin{array}{l}\text { Seismicity } \\
\text { (magnitude) }\end{array}$ & $\begin{array}{c}1-7,5 ; \\
2-6,5 ; \\
4-\text { less than } 6,5 \\
\end{array}$ \\
\hline $\begin{array}{l}\text { Underlying rock } \\
\text { structures }\end{array}$ & $\begin{array}{c}1 \text { - chalk, gypsum, } \\
\text { anthracites, marls, } \\
\text { coal, clays, loess, } \\
\text { gravel } \\
2 \text { - sandstones, } \\
\text { limestones, } \\
\text { conglomerates, } \\
\text { slates } \\
3 \text { - dolomites, } \\
\text { marble, shale } \\
\text { sandstones } \\
4 \text { - quartzites, } \\
\text { basalts, andesites, } \\
\text { dacites, granites, } \\
\text { gneisses, syenites, } \\
\text { diorites, } \\
\text { monzonites }\end{array}$ \\
\hline Slope & $\begin{array}{c}1 \text { - more than } 30 \\
\text { degrees; } \\
2-20-30 \\
\text { degrees; } \\
3-10-20 \\
\text { degrees; } \\
4 \text { - less than } 10 \\
\text { degrees }\end{array}$ \\
\hline $\begin{array}{l}\text { Presence of mining } \\
\text { sites }\end{array}$ & $\begin{array}{c}1-0-1000 \mathrm{~m} ; \\
2-1000-3000 \mathrm{~m} ; \\
3-3000-10000 \\
\mathrm{~m} ; \\
4-\text { more than } \\
10000 \mathrm{~m} \\
\end{array}$ \\
\hline
\end{tabular}




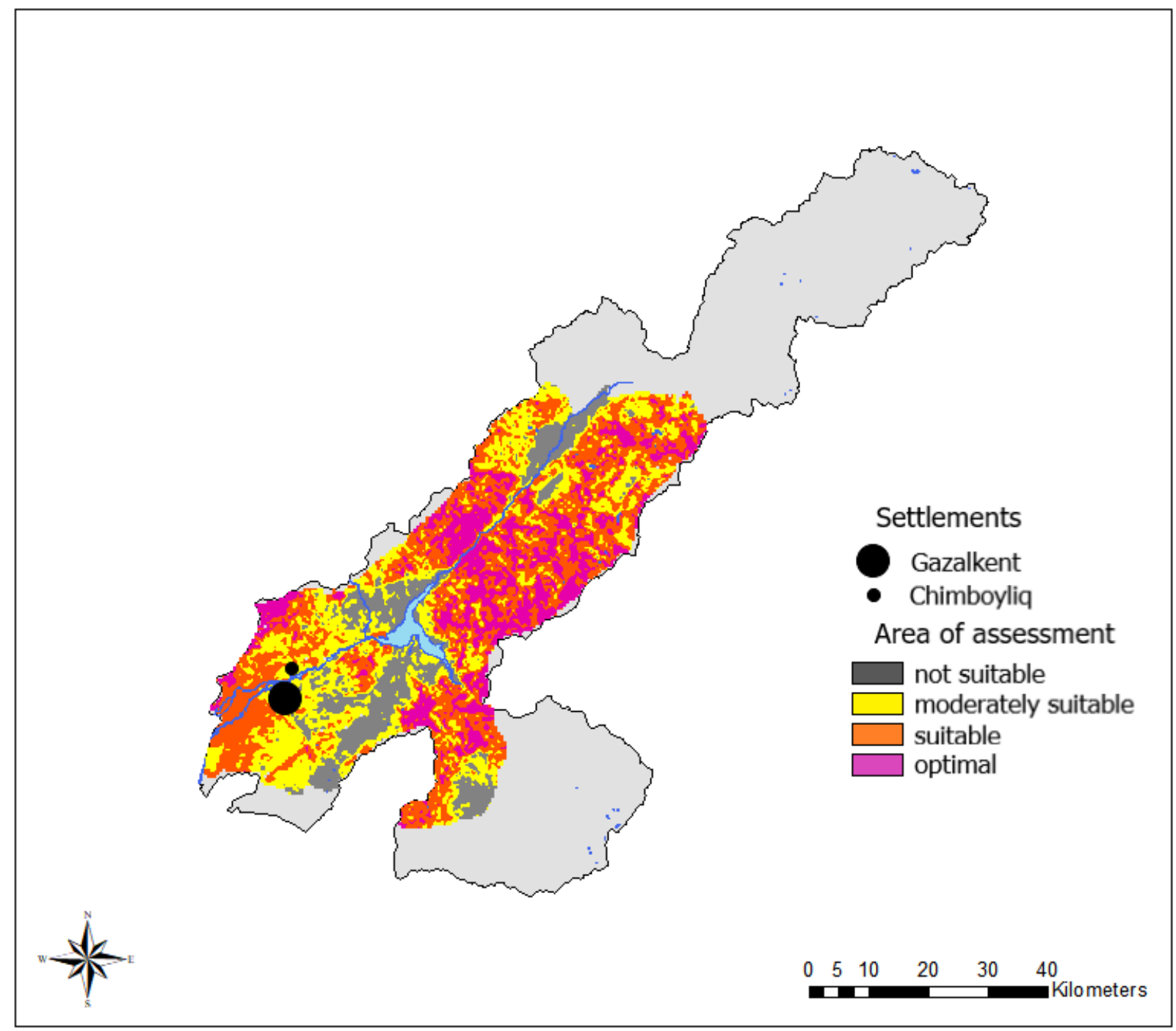

Fig. 4. Assessment of territory of Bostanliq district according to the degree of suitability for the development of wind energy using the GIS analytic (by author)

The map demonstrates that the areas confined to water bodies and the adjacent territory are unfavorable and unsuitable, as they are composed of unstable predominantly Quaternary rocks (clays, sands, and marls), which are at risk of landslide processes. This territories also cause conflicts with agricultural nature management as they're used for arable land and gardens.

Areas in the southwest and southeast of the region can be considered moderately suitable. Mostly, these territories are also composed of slightly unstable rocks (pebbles and conglomerates covered with loess) and heavily dissected by ravine networks, as well as are actively used for agriculture. However, most of them are also favorable in terms of infrastructure, and a significant percentage of end consumers of electricity live here.

Suitable areas are scattered throughout the study site and are characterized by great meteorological conditions, the hardness of underlying rocks, sufficient level of transport and energy infrastructure, presence of a consumer, low landslide activity, and medium relative altitudes (500-1000 meters).

Optimal areas for the potential installation of wind turbines are located mainly in the lower course of the Pskem River valley. However, despite the high wind characteristics and rock 
hardness, some areas that are comprehensively calculated as the most optimal also have several limitations (lack of power lines, the remoteness of nearby railways, partial capture of the Menzbier's marmot habitat, the prevalence of slopes of medium steepness).

\section{CONCLUSIONS}

The energy transition is a recognized global trend. The Republic of Uzbekistan with one of the largest economies of Central Asia demonstrates great interest in the development of renewable energy sources and has already brought it into action through the installation of the first experimental wind turbine with a height of 52 meters in the village of Yubileiny (Bostanliq district) in 2012 [Zhamolov et al., 2019]. The next step is the construction of a wind farm. The development of local renewable energy sources is essential for the Bostanliq district in connection with the emerging trend of economic growth of the region and the popularization of tourism.

Upon the assessment of Bostanliq district the territory based on the wind energy potential, the following was established:

1. due to geological and geomorphological specifics of the region, there are few suitable places for the construction of a wind park;

2. the optimal spots are located mainly in the lower course of the Pskem River valley and are characterized by favorable meteorological characteristics, the absence of landslide bodies, and the hardness of the underlying rocks;

3. the proposed method for assessing territories based on the potential for wind energy development using the ArcMap software can be applied to any region of the world with amendments for the specifics of physical, geographical, and socio-economic conditions of the study area.

\section{ACKNOWLEDGEMENTS}

The study was carried out as part of the expedition "Dynamics of landscapes and nature management of northeastern Uzbekistan" of the Department of Physical Geography and Landscape Science (Faculty of Geography, Lomonosov Moscow State University) in JanuaryFebruary of 2020 with the financial support of the National University of Uzbekistan named after Mirzo Ulugbek (Tashkent).

\section{REFERENCES}

1. Belousov S.L. A guide to short-term weather forecasts. Middle Asia. Russia, St. Petersburg: Gidrometeoizdat, 1986. 320 p. (in Russian)

2. Berezkin M.Yu., Sinyugin O.A. Geography of investment in the renewable energy sector of the world. Vestnik Moskovskogo universiteta. Seriya 5, Geografiya. 2018. V. 4. P. 68-74. (in Russian).

3. Elistratov V.V., Kuznetsov M.V. Theoretical Framework of Alternative and Renewable Energy. Saint Petersburg, Russia: Peter the Great St.Petersburg Polytechnic University, 2003. 55 p. (in Russian).

4. Islomov I.N., Zhumataev R.B. About the most important suburban areas of agricultural production (on the example of the city of Tashkent). Academy, 2019. V. 6. P. 77-79 (in Russian)

5. Juliev M., Pulatov A., Hübl J. Natural hazards in mountain regions of Uzbekistan: A review of mass movement processes in Tashkent province. International Journal of Scientific \& Engineering Research, 2017. V. 8. P. 1102-1108.

6. Kim H.-G., Kang Y.-H., Hwang H.-J., Yun C.-Y. Evaluation of Onshore Wind Resource Potential According to Environmental Conservation Value Assessment. Energy Procedia, 2014. V. 57. P. 773-781. 
7. Lee M. Knowledge and landscape in wind energy planning. Legal Studies, 2017. V. 37. P. 3-24.

8. Prinsloo F.C. Impact of renewable energy structures on tourism. South Africa, Stellenbosch: University of Stellenbosch, 2013. 10 p.

9. Sayigh A. Comprehensive renewable energy. Amsterdam, Netherlands: Elsevier, 2012. $4422 \mathrm{p}$.

10. Sissingh J., Arends E. Wind Energy Potential Vietnam. Utrecht, Netherlands: Netherlands Enterprise Agency, 2019. 81 p.

11. Van Haaren R., Fthenakis $V$. GIS-based wind farm site selection using spatial multi-criteria analysis (SMCA): Evaluating the case for New York State. Renewable and Sustainable Energy Reviews, 2011. V. 15. P. 3332-3340.

12. Zhamolov T.R., Gofurov D.S., Murodov F.B. Analysis of the potential of wind energy in the conditions of the Tashkent region. Universum: Technical science, 2019. V. 61. P. 6367 (in Russian) 